\title{
Mitochondrial Protein Import: Nucleoside Triphosphates Are Involved in Conferring Import-Competence to Precursors
}

\author{
Nikolaus Pfanner, Maximilian Tropschug, \\ and Walter Neupert \\ Institut für Physiologische Chemie \\ der Universität München \\ Goethestr. 33 \\ D-8000 München 2, FRG
}

\section{Summary}

The role of nucleoside triphosphates (NTPs) in mitochondrial protein import was investigated with the precursors of $N$. crassa ADP/ATP carrier, $F_{1}$-ATPase subunit $\beta, F_{0}$-ATPase subunit 9 , and fusion proteins between subunit 9 and mouse dihydrofolate reductase. NTPs were necessary for the initial interaction of precursors with the mitochondria and for the completion of translocation of precursors from the mitochondrial surface into the mitochondria. Higher levels of NTPs were required for the latter reactions as compared with the early stages of import. Import of precursors having identical presequences but different mature protein parts required different levels of NTPs. The sensitivity of precursors in reticulocyte lysate to proteases was decreased by removal of NTPs and increased by their readdition. We suggest that the hydrolysis of NTPs is involved in modulating the folding state of precursors in the cytosol, thereby conferring import competence.

Introduction

Transport of cytoplasmically synthesized precursor proteins into mitochondria involves several consecutive steps (for review see Hay et al., 1984; Harmey and Neupert, 1985; Pfanner and Neupert, 1987a). The precursors bind to specific receptor sites on the mitochondrial surface (Hennig and Neupert, 1981; Gasser et al., 1982; Hennig et al., 1983; Zwizinski et al., 1983, 1984; Riezman et al., 1983; Pfaller et al., 1985; Schmidt et al., 1985; Hartl et al., 1986; Pfanner and Neupert, 1987b). Translocation into or across the inner mitochondrial membrane takes place at contact sites between the outer and inner membranes (Schleyer and Neupert, 1985; Hartl et al., 1986; Pfanner and Neupert, 1987b; Schwaiger et al., 1987) and requires the electrical potential $(\Delta \psi)$ across the inner membrane (Schleyer et al., 1982; Gasser et al., 1982; Kolanski et al., 1982; Pfanner and Neupert, 1985). The role of $\Delta \psi$ is assumed to be an electrophoretic effect on positively charged parts of the precursor molecules (Pfanner and Neupert, 1985; Roise et al., 1986). The import of $F_{0} F_{1}$ ATPase subunit $\beta\left(F_{1} \beta\right)$ has been demonstrated to require both $\Delta \psi$ and nucleoside triphosphates (NTPs). Nonhydrolyzable ATP analogues are not able to fulfill the NTP requirement, suggesting that hydrolysis of high energy phosphate bonds is necessary (Pfanner and Neupert, 1986). Precursor proteins with amino-terminal prese- quences are proteolytically cleaved by the processing peptidase located in the matrix (Böhni et al., 1980, 1983; Conboy et al., 1982; McAda and Douglas, 1982; Miura et al., 1982; Zwizinski and Neupert, 1983; Schmidt et al., 1984). The presequences apparently carry sufficient information for the targeting of proteins to mitochondria (Hurt et al., 1984, 1985; Horwich et al., 1985; Emr et al., 1986 Keng et al., 1986; van Loon and Young, 1986). Presequences also seem to be important for the intramitochondrial sorting of precursors (van Loon et al., 1986; Hartl et al., 1986).

For several precursor proteins, the import pathway has been resolved into distinct steps. For example, the import of $F_{1} \beta$ and subunits IV (cytochrome $c_{1}$ ) and $V$ (FeS protein) of the $b c_{1}$-complex can be blocked at the level of translocation contact sites (Schleyer and Neupert, 1985; Hartl et al., 1986; see Figure 8A, stage b). At this stage, the amino-terminal parts of the precursors are exposed to the mitochondrial matrix, where they are proteolytically processed, whereas carboxy-terminal parts are still outside the outer membrane. These translocational intermediates can be completely imported by relieving the translocation block.

The import of ADPIATP carrier involves the following steps (the distinct forms of ADP/ATP carrier on the import pathway are named from stage 1 to stage 5 [Pfanner and Neupert, 1987b; see Figure 8B]). The precursor is synthesized in the cytoplasm without a cleavable presequence (stage 1) (Zimmermann et al., 1979; Arends and Sebald, 1984). It binds to receptor sites on the mitochondrial surface (stage 2) and is then directed to protease-protected sites in the outer membrane (stage 3 ). The $\Delta \psi$-dependent entrance into the inner membrane occurs at contact sites (stage 4). The completion of transiocation into the inner membrane and the assembly to the functional dimer (stage 5) do not require $\Delta \psi$.

To investigate the role of NTPS in the transport of proteins into mitochondria, the distinct steps on the import pathways of $F_{1} \beta$ and ADPIATP carrier were tested for their requirement of NTPS. We find that several steps need NTPs independently of whether the specific binding to mitochondria or the $\Delta \psi$-dependent step have already taken place. The common feature of the NTP-requiring steps is that they all involve translocation of parts of precursors from the cytosol into the mitochondrial membranes. Resistance to so-called unspecific proteases (e.g., proteinase $\mathrm{K}$ ) has been used to test the degree of folding of proteins: a high protease resistance suggests a high degree of tertiary structure, whereas proteins with less tertiary structure are usually very sensitive to unspecific proteases (for review see Jaenicke and Rudolph, 1986; Randall and Hardy, 1986). In the absence of NTPs, the protease resistance of mitochondrial precursor proteins in rabbit reticulocyte lysate was increased, whereas addition of NTPs decreased the protease resistance. We conclude that the role of NTPs in mitochondrial protein import involves unfolding of precursor proteins in the cytosol. 


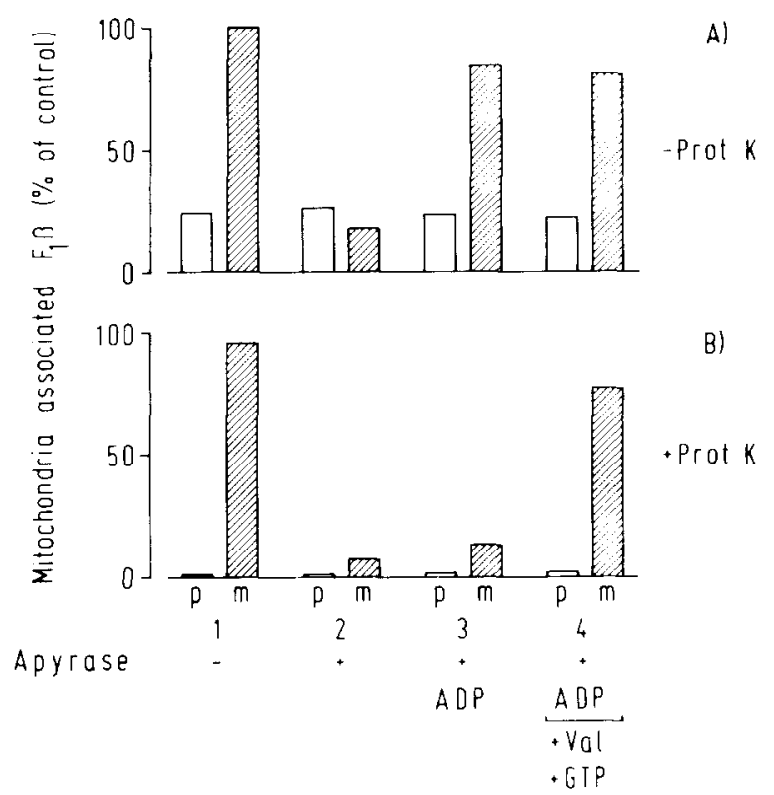

Figure 1. Transport of $F_{1} \beta$ into Contact Sites and Completion of Import Require NTPs

Isolated mitochondria ( $2.5 \mathrm{mg}$ of mitochondrial protein per $\mathrm{ml}$ ) and reticulocyte lysate (containing radiolabeled precursor proteins) were treated with apyrase $(0.5 \mathrm{U} / \mathrm{ml})$ (reactions $2-4)$ or received an apyrase preparation that had been heated to $95^{\circ} \mathrm{C}$ before use (corresponding to $0.5 \mathrm{U} / \mathrm{ml}$ ) (reaction 1). Mitochondria were added to the reticulocyte lysate in a mixture containing antimycin $A$, oligomycin, potassium ascorbate, TMPD, and BSA-containing buffer (for details see Experimental Procedures; Pfanner and Neupert, 1986). Reactions 3 and 4 contained $6 \mathrm{mM}$ ADP. All samples were incubated for $25 \mathrm{~min}$ at $25^{\circ} \mathrm{C}$. Reactions 1-3 were divided, and one-half was treated with proteinase $\mathrm{K}(15 \mu \mathrm{g} / \mathrm{ml}$, final concentration) $(\mathrm{B} ;+$ Prot $\mathrm{K})$. Mitochondria of reaction 4 were reisolated and resuspended in BSA-containing buffer in the presence of valinomycin (Val); GTP was added ( $6 \mathrm{mM}$, final concentration), and the sample was incubated at $25^{\circ} \mathrm{C}$ for $15 \mathrm{~min}$. The reaction was then divided, and one-half was treated with proteinase $\mathrm{K}(15 \mu \mathrm{g} / \mathrm{ml}$, final concentration). Mitochondria were reisolated from all samples. $F_{1} \beta$ was immunoprecipitated, and samples were resolved by SDSpolyacrylamide gel electrophoresis. Quantitation of the fluorograms was performed by densitometry. $p$, precursor of $F_{1} \beta ; m$, mature-sized form of $F_{1} \beta$.

\section{Results}

Insertion of the Precursor to $F_{1} \beta$ into Translocation Contact Sites and the Completion of Translocation into the Matrix Require NTPs

Preincubation of reticulocyte lysate, containing in vitrosynthesized mitochondrial precursor proteins, and of mitochondria with apyrase (an adenosine 5'-triphosphatase and an adenosine 5 '-diphosphatase) inhibited the import of $F_{1} \beta$ into mitochondria. Readdition of ATP or GTP restored import. A mitochondrial membrane potential was established by addition of ascorbate plus $N, N, N^{\prime}, N^{\prime}-$ tetramethylphenylenediamine (TMPD), which supplies electrons at the level of complex IV of the electron transport chain (Nicholls, 1982; Wikstrom and Krab, 1982). Oligomycin was added to prevent dissipation of $\Delta \psi$ and formation of ATP by the $F_{0} F_{1}$-ATPase. These studies showed that the import of $F_{1} \beta$ needs NTPs in addition to

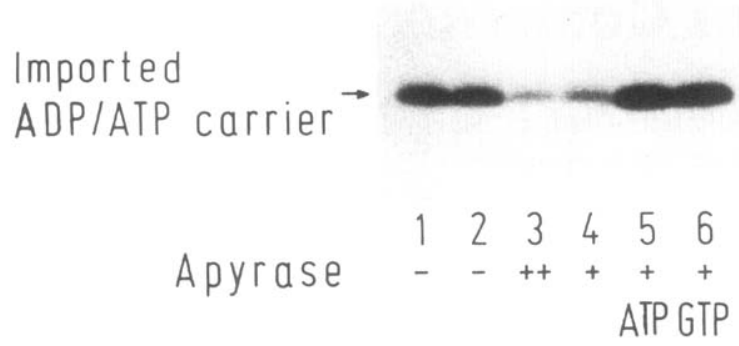

Figure 2. Import of ADP/ATP Carrier Requires NTPs

Mitochondria and reticulocyte lysate were incubated with apyrase (80 $\mathrm{U} / \mathrm{ml}$ for reaction $3 ; 0.5 \mathrm{U} / \mathrm{ml}$ for reactions 4-6), an apyrase preparation that had been heated before use (corresponding to $80 \mathrm{U} / \mathrm{ml}$; reaction 2), or water (reaction 1). Mitochondria and reticulocyte lysate were combined and incubated in the presence of antimycin A, oligomycin, potassium ascorbate, TMPD, and BSA-containing buffer. Reactions 5 and 6 contained $8 \mathrm{mM}$ ATP or GTP. After $25 \mathrm{~min}$ at $25^{\circ} \mathrm{C}$, samples were treated with proteinase $\mathrm{K}(200 \mu \mathrm{g} / \mathrm{ml}$, final concentration). Mitochondria were reisolated, and assembled ADP/ATP carrier was assessed by hydroxylapatite chromatography. $(+), 0.5 U$ of apyrase per $\mathrm{ml} ;(++), 80 \mathrm{U}$ of apyrase per $\mathrm{ml}$.

a membrane potential (Pfanner and Neupert, 1986). This system was also used for the experiments described in this report.

After treatment with apyrase $(0.5 \mathrm{U} / \mathrm{ml})$, reticulocyte lysate and mitochondria were mixed and incubated at $25^{\circ} \mathrm{C}$; specific processing of $F_{1} \beta$ (Figure $1 A$, reaction 2 ) and transport to a protease-protected location (Figure 1B, reaction 2) were strongly inhibited. The control (Figure 1, reaction 1) showed processing of $F_{1} \beta$ and protection of mature-sized $F_{1} \beta\left(m-F_{1} \beta\right)$ from proteases; protease protection is correlated with transport of $F_{1} \beta$ into the matrix (Zwizinski and Neupert, 1983; Schleyer and Neupert, 1985). When, after treatment with apyrase, ADP was added, the specific processing to $m-F_{1} \beta$ was restored (Figure 1A, reaction 3 ). This $m-F_{1} \beta$, however, was still sensitive to proteases from the outside of mitochondria (Figure 1B, reaction 3). Thus, the amino terminus of this $F_{1} \beta$ had already entered the matrix space, whereas a major portion was still outside the outer membrane; apparently, this $m-F_{1} \beta$ was spanning translocation contact sites (Schleyer and Neupert, 1985; Hartl et al., 1986). The mitochondria of reaction 4 were reisolated after incubation in the presence of ADP. They were resuspended in buffer containing bovine serum albumin (BSA) (Pfanner and Neupert, 1985) in the absence of a membrane potential (Schleyer and Neupert, 1985; Hartl et al., 1986; Pfanner and Neupert, 1987b). GTP was added, and a second incubation at $25^{\circ} \mathrm{C}$ was performed. Thereby, the $m-F_{1} \beta$ that was spanning contact sites was chased to proteaseprotected $m-F_{1} \beta$ (Figure $1 B$. reaction 4 ).

The restoration of processing by the addition of ADP, but not of ATP, could be inhibited by $P^{1}, P^{5}$-bis-(adenosine-5) pentaphosphate $\left(A p_{5} A\right)$, an inhibitor of adenylate kinase that catalyzes the reaction $2 \mathrm{ADP} \rightleftharpoons \mathrm{ATP}+\mathrm{AMP}$ (for review see Frank et al., 1984) (data not shown). The restoration is therefore dependent on ATP generated from ADP (addition of AMP did not lead to restoration). The ac- 


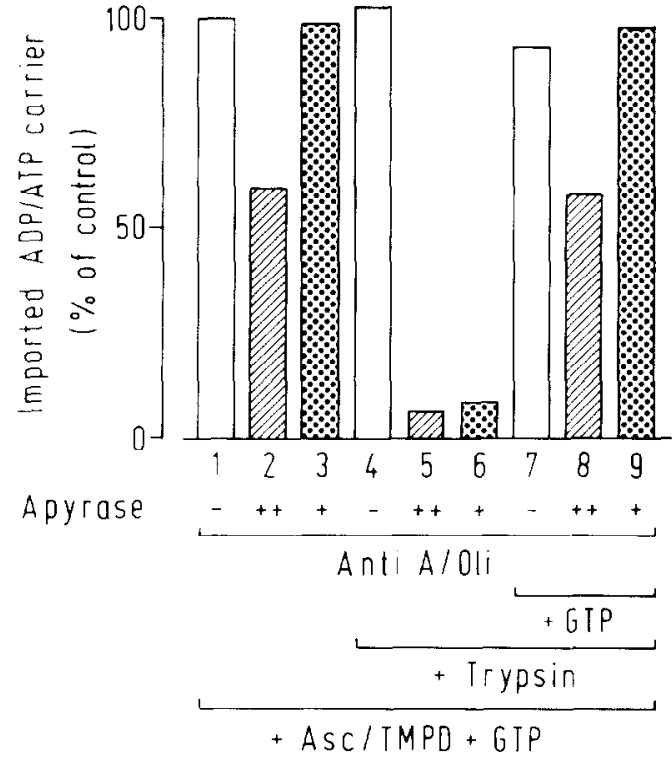

Figure 3. Binding of ADP/ATP Carrier to the Mitochondrial Surface and Insertion into the Outer Membrane Require NTPs

Mitochondria and reticulocyte lysate were incubated with an apyrase preparation that had been heated before use (corresponding to 80 $\mathrm{U} / \mathrm{ml}$, mixture a), apyrase $(80 \mathrm{U} / \mathrm{ml}$, mixture b), or apyrase $(0.5 \mathrm{U} / \mathrm{ml}$, mixture $c$ ). Mitochondria and reticulocyte lysate were combined and incubated in the presence of antimycin A (Anti A), oligomycin (Oli), and $B S A$-containing buffer for $25 \mathrm{~min}$ at $25^{\circ} \mathrm{C}$. Mitochondria were reisolated and resuspended in BSA-containing buffer in the presence of antimycin A, oligomycin, and an apyrase preparation that had been heated before use (corresponding to $0.2 \mathrm{U} / \mathrm{ml}$, mixture a) or apyrase $(0.2 \mathrm{U} / \mathrm{ml}$, mixtures $b$ and $c$ ). Each mixture was divided into three portions (mixture a into reactions 1,4 , and 7 ; mixture $b$ into 2,5 , and 8 ; mixture $c$ into 3,6 , and 9). One set of reactions (4-6) was treated with trypsin (15 $\mu \mathrm{g} / \mathrm{ml}$ final concentration). Reactions $1-3$ received the same volume of SEM medium. Reactions 7-9 received $6 \mathrm{mM}$ GTP and were incubated for $15 \mathrm{~min}$ at $25^{\circ} \mathrm{C}$, followed by treatment with trypsin ( 15 $\mu \mathrm{g} / \mathrm{ml}$, final concentration). All reactions received potassium ascorbate (Asc), TMPD, and $8 \mathrm{mM} \mathrm{GTP}$ and were incubated for $15 \mathrm{~min}$ at $25^{\circ} \mathrm{C}$. Mitochondria were reisolated again, and assembled ADPIATP carrier was assessed by hydroxylapatite chromatography. $(+), 0.5 \mathrm{U}$ of apyrase per $\mathrm{ml} ;(++), 80 \mathrm{U}$ of apyrase per $\mathrm{ml}$.

cumulation of $m-F_{1} \beta$ that was spanning translocation contact sites seen in reaction 3 of Figure 1 was also obtained when the pretreatment was performed with lower concentrations of apyrase (without addition of ADP) or when at higher apyrase concentrations, ATP was added.

In summary, transport of $F_{1} \beta$ into contact sites requires NTPs. The completion of import, however, needs higher levels of NTPs (see Figure 8A). The completion is independent of the membrane potential (Schleyer and Neupert, 1985).

\section{Specific Binding of ADP/ATP Carrier to the Mitochondrial Surface and Insertion into the Outer Membrane Require NTPs}

Reticulocyte lysate and mitochondria were pretreated with apyrase as described for the experiments with $F_{1} \beta$ (see above; Pfanner and Neupert, 1986). Under these conditions, the import of ADPIATP carrier was also inhibited
(Figure 2, reactions 3 and 4). Addition of ATP or GTP restored import (Figure 2, reactions 5 and 6 ); the import was even stimulated over the control values (reactions 1 and 2). The import of ADP/ATP carrier into the inner membrane was tested by protection against high concentrations of proteinase $K$ and by the carboxyatractylosidedependent passage over hydroxylapatite, a convenient assay for the assembly of the ADPIATP carrier (Schleyer and Neupert, 1984; Pfanner and Neupert, 1987b).

Which steps on the import pathway of ADP/ATP carrier need NTPS? In the absence of $\Delta \psi$, the import of ADPIATP carrier into the inner membrane is blocked, but the precursor to the ADPIATP carrier can still bind to specific sites on the mitochondrial surface from which it can be imported after reestablishing $\Delta \psi$ (see Introduction; Zwizinski et al., 1983; Pfanner and Neupert, 1987b). In the experiment described in Figure 3, reticulocyte lysate and mitochondria were pretreated with apyrase $(80 \mathrm{U} / \mathrm{ml}$ or 0.5 $\mathrm{U} / \mathrm{ml}$ ). Controls received an apyrase preparation that had been heated before use. Reticulocyte lysate and mitochondria were then mixed and incubated at $25^{\circ} \mathrm{C}$ in the presence of antimycin $A$ and oligomycin, which destroy the mitochondrial membrane potential (Nicholls, 1982; Wikstrom and Krab, 1982). Mitochondria were reisolated and resuspended in BSA-containing buffer in the presence of antimycin A, oligomycin, and apyrase. The mixtures were divided into three portions, each. The first portions (Figure 3 , reactions $1-3$ ) were left untreated, whereas the second portions (reactions 4-6) were treated with trypsin at a concentration that preserves the stage 3 intermediate in the outer membrane but degrades the receptor-bound stage 2 intermediate (see Introduction; Pfanner and Neupert, 1987b). A membrane potential was then established in both groups by addition of ascorbate plus TMPD, and NTPs were added. After incubation at $25^{\circ} \mathrm{C}$, mitochondria were reisolated again and assayed for imported ADP/ATP carrier. Specific (i.e., import-competent) binding of ADPIATP carrier still occurred after treatment with apyrase (Figure 3, reactions 2 and 3 ). This specifically bound precursor was sensitive to trypsin treatment (Figure 3, reactions 5 and 6) (stage 2 intermediate), whereas in the control reaction (reaction 4 ) the precursor was already inserted into a protease-protected location in the outer membrane (stage 3 ). The third group of portions (Figure 3, reactions 7-9) received NTPs, in the absence of $\Delta \psi$, after the first reisolation of mitochondria and was then incubated at $25^{\circ} \mathrm{C}$. Treatment with trypsin and further additions were performed as described for reactions 4-6. Thereby, the stage 2 intermediate could be chased to the protease-protected stage 3 intermediate, and then to assembled inner membrane ADPIATP carrier (Figure 3 , reactions 8 and 9 ).

We conclude that the insertion of the ADPIATP carrier into the outer membrane strongly depends on the presence of NTPs. Since pretreatment with high apyrase concentrations reduced the amount of specifically bound precursor (Figure 3 , reactions 2 and 8 ), binding to receptor sites on the mitochondrial surface also seems to require NTPS. 


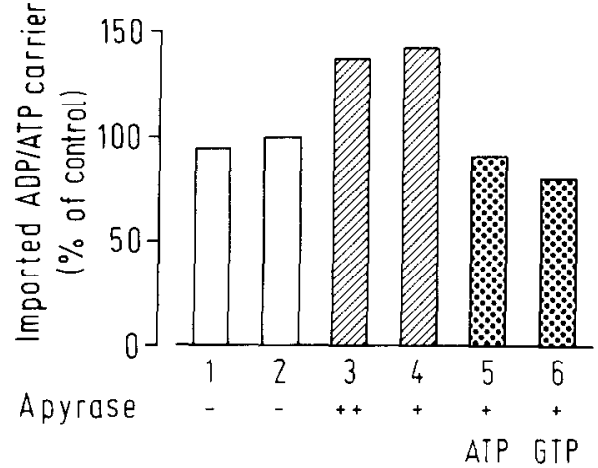

Figure 4. Transport of ADP/ATP Carrier from the Outer Membrane into the Inner Membrane Is Stimulated by Removal of NTPS

Mitochondria, reticulocyte lysate, antimycin $\mathrm{A}$, and oligomycin were incubated for $25 \mathrm{~min}$ at $25^{\circ} \mathrm{C}$. Mitochondria were reisolated and suspended in BSA-containing buffer in the presence of antimycin $A$ and oligomycin. Samples were incubated with apyrase $(20 \mathrm{U} / \mathrm{ml}$ for reaction 3; $0.13 \mathrm{U} / \mathrm{ml}$ for reactions $4-6$ ), an apyrase preparation that had been heated before use (corresponding to $20 \mathrm{U} / \mathrm{ml}$ for reaction 2), or water (reaction 1) for $20 \mathrm{~min}$ at $25^{\circ} \mathrm{C}$. All samples received potassium ascorbate and TMPD. In addition, sample 5 received $8 \mathrm{mM}$ ATP and sample 6 received $8 \mathrm{mM}$ GTP. All samples were incubated for $15 \mathrm{~min}$ at $25^{\circ} \mathrm{C}$ and then treated with proteinase $\mathrm{K}(200 \mu \mathrm{g} / \mathrm{ml}$, final concentration). Mitochondria were reisolated, and assembled ADP/ATP carrier was assessed by hydroxylapatite chromatography. Similar results were obtained when the import of ADPIATP carrier was determined by protection against high concentrations of proteinase $\mathrm{K}(200 \mu \mathrm{g} / \mathrm{ml}) .(+)$ $0.13 \mathrm{U}$ of apyrase per $\mathrm{ml} ;(++), 20 \mathrm{U}$ of apyrase per $\mathrm{ml}$.

Transport of ADP/ATP Carrier from the Outer Membrane into the Inner Membrane and Assembly to the Dimeric Form Do Not Require NTPs

The precursor to the ADPIATP carrier was bound to mitochondria in the absence of $\Delta \psi$ at $25^{\circ} \mathrm{C}$. Thereby, the stage 3 intermediate, which is inserted into the outer membrane, was generated. After reisolation, mitochondria were resuspended in BSA-containing buffer in the absence of a $\Delta \psi$ and treated with apyrase (Figure 4, reactions 3-6) or not treated (reactions 1 and 2). A membrane potential was then established. In addition, reactions 5 and 6 (Figure 4) received NTPs. After incubation at $25^{\circ} \mathrm{C}$, imported and assembled ADPIATP carrier was determined. The removal of NTPs did not inhibit the import of the stage 3 ADPIATP carrier, but rather stimulated it (Figure 4, reactions 3 and 4). Readdition of NTPs (Figure 4, reactions 5 and 6) reduced the translocation of precursors from the outer into the inner membrane to (and even below) the control values (reactions 1 and 2). In separate experiments it was demonstrated for endogenous mitochondrial ADPIATP carrier that the protease resistance in intact mitochondria and the ability to pass over hydroxylapatite were not affected by modifying the concentrations of NTPs (data not shown).

In summary, the various steps on the import pathway of ADPIATP carrier require different levels of NTPs. Binding to receptor sites on the mitochondrial surface requires lower levels than insertion into the outer membrane. There is no demonstrable requirement for transport from the outer into the inner membrane (see Figure 8B).

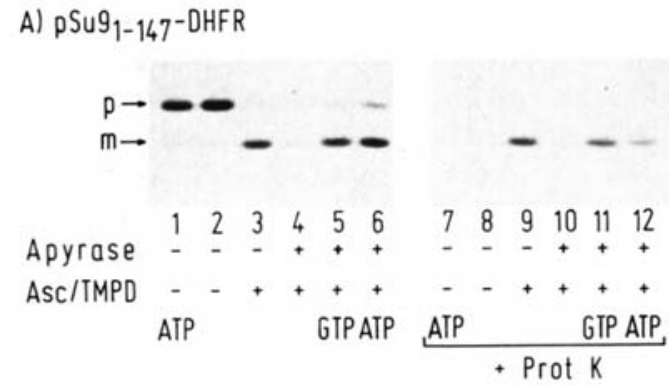

B) $p S \cup 9_{1-69-D H F R}$

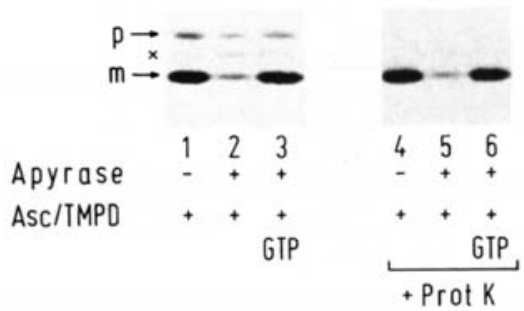

Figure 5. Import of ATPase Subunit 9-DHFR Fusion Proteins Requires NTPS

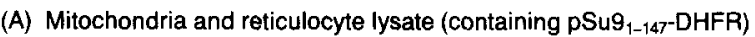
were incubated with apyrase $(0.5 \mathrm{U} / \mathrm{ml}$, reactions $4-6$ and $10-12)$ or an apyrase preparation that had been heated before use (corresponding to $0.5 \mathrm{U} / \mathrm{ml}$, reactions $1-3$ and 7-9). Mitochondria and reticulocyte lysate were combined and incubated in the presence of antimycin $A$, oligomycin, and BSA-containing buffer. Reactions 3-6 and 9-12 contained potassium ascorbate (Asc) and TMPD. Reactions 1, 6, 7, and 12 contained $8 \mathrm{mM}$ ATP. Reactions 5 and 11 contained $8 \mathrm{mM}$ GTP. All reactions were incubated for $25 \mathrm{~min}$ at $25^{\circ} \mathrm{C}$. Reactions 7-12 were treated with proteinase $\mathrm{K}(25 \mu \mathrm{g} / \mathrm{ml}$ final concentration) (Prot K). Mitochondria were reisolated, and samples were resolved by SDS-polyacrylamide gel electrophoresis. $p$, precursor form; $m$, mature-sized form.

(B) The experiment was performed as described for reactions $3-5$ and 9-11 of (A) with the following modifications. Reticulocye lysate containing pSu $9_{1-69}$-DHFR was used. The apyrase concentration was 16 $\mathrm{U} / \mathrm{ml}$. p, precursor form; $m$, mature-sized form. The band indicated with " $x$ " could represent a processing intermediate of the fusion protein. Such a processing intermediate, with the same differences in apparent molecular weight between precursor form and mature form, has been identified for native ATPase subunit 9 by radiosequencing (Schmidt et al., 1984).

Fusion Proteins Containing Nonmitochondrial Polypeptides Also Require NTPs for Import into Mitochondria

Is the requirement for NTPs a general phenomenon of mitochondrial protein import? We studied whether proteins containing large nonmitochondrial parts also show this requirement. The following fusion proteins were constructed by combining different parts of the coding region for the precursor to $F_{0}$-ATPase subunit 9 of Neurospora crassa (Viebrock et al., 1982) and for mouse dihydrofolate reductase (DHFR) (Nunberg et al., 1980), a cytosolic protein: complete subunit 9 precursor (amino-terminal) + DHFR (carboxy-terminal) (pSu9 1-14T DHFR; Figure 5A); presequence and 3 amino acids of the mature subunit 9 (amino-terminal) + DHFR (carboxy-terminal) $\left(\mathrm{pSu}_{1-69}\right.$ DHFR; Figure 5B).

Both fusion proteins were processed by isolated Neurospora mitochondria (Figure 5A, reaction 3; Figure 5B, 


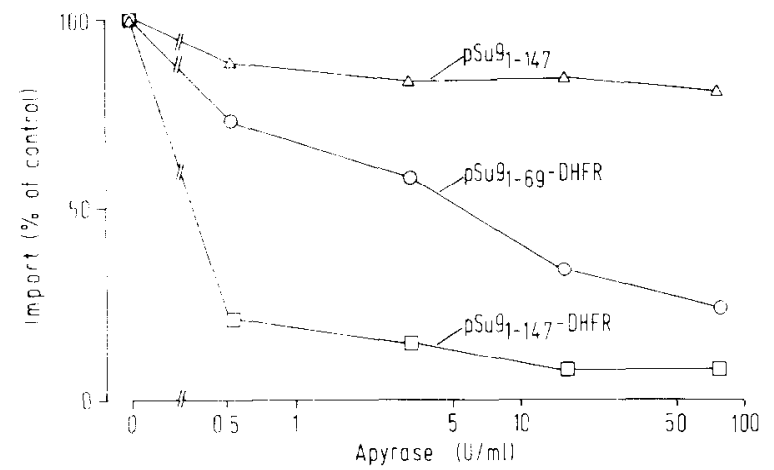

Figure 6. Import of Precursors Having Identical Presequences but Dlfferent Mature Protein Parts Requires Different Levels of NTPs

The experiment was performed as described in Figure 5A, reactions 3 and 4 , with the following modifications. Reticulocyte lysate contained the precursors to either native ATPase subunit $9\left(\mathrm{pSu}_{1-147}\right)$ or fusion proteins pSu $_{1-69}$-DHFR or pSu $9_{1-147}$-DHFR. The apyrase concentrations used were as indicated. Results were quantified by densitometry of the bands corresponding to the mature-sized proteins. Similar results were obtained when protease protection of the mature-sized fusion proteins was tested.

reaction 1). Incubation of the fusion proteins with the purified processing peptidase of the mitochondrial matrix yielded products with the same apparent molecular weight (Hawlitschek and Neupert, unpublished data). The mature-sized proteins generated by intact mitochondria were protected against externally added proteases (Figure $5 \mathrm{~A}$, reaction 9; Figure $5 \mathrm{~B}$, reaction 4). Dissipation of $\Delta \psi$, by addition of antimycin A plus oligomycin, inhibited the processing and transport to a protease-protected location (Figure 5A, reactions 2 and 8 ; and data not shown). ATP could not substitute for the requirement of $\Delta \psi$ (Figure $5 A$, reactions 1 and 7 ). When mitochondria and reticulocyte lysate were pretreated with apyrase, then mixed together and a membrane potential established, the processing and transport to a protease-protected location were inhibited (Figure 5A, reactions 4 and 10; Figure 5B, reactions 2 and 5 ). Readdition of NTPs restored the import of the fusion proteins (Figure $5 \mathrm{~A}$, reactions $5,6,11$, and 12; Figure $5 B$, reactions 3 and 6 ). Thus, the import of the fusion proteins needs both $\Delta \psi$ and NTPs.

\section{Import of Precursors Having Identical Presequences but Different Mature Protein Parts Requires Different Levels of NTPs}

Mitochondria and reticulocyte lysate were pretreated with different concentrations of apyrase. Then, the proteolytic processing and transport to a protease-protected location were tested for both fusion proteins and the native subunit 9 precursor (Figure 6). The import of subunit 9 precursor (pSu9 ${ }_{1-147}$ ) was only slightly inhibited, even with high apyrase concentrations. The import of the longer fusion protein (pSu9 ${ }_{1-147}$-DHFR) was already inhibited at low apyrase concentrations. The import of the shorter fusion

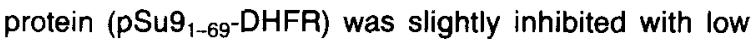
apyrase concentrations, but more strongly inhibited with higher apyrase concentrations.

Thus, the import of three precursors having identical
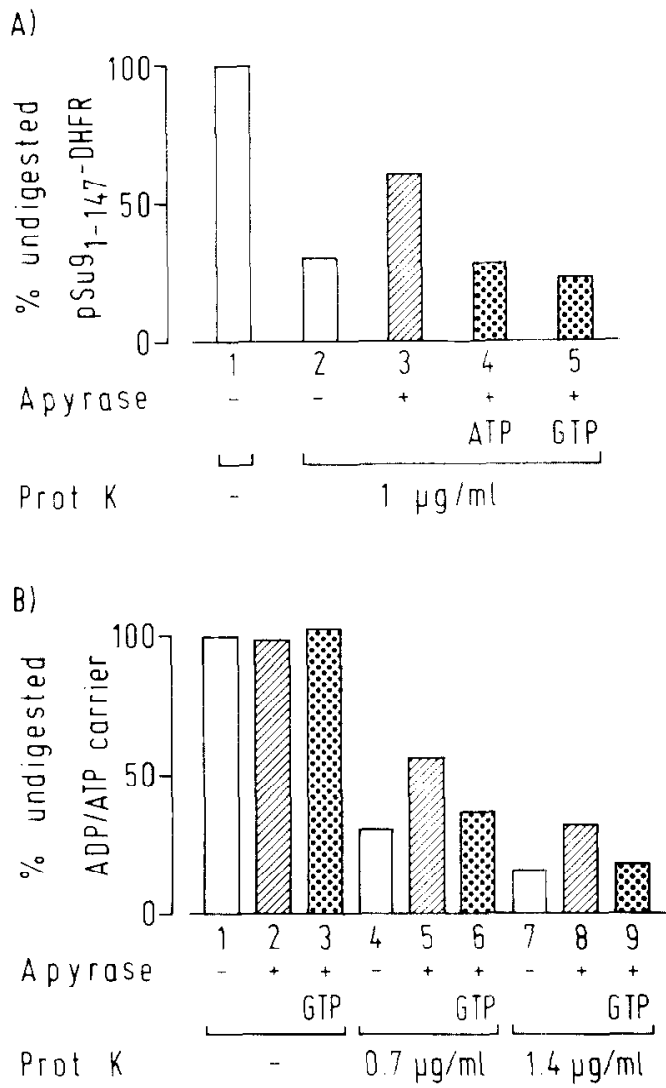

Figure 7. NTPS Decrease the Protease Resistance of in Vitro- Synthesized Precursor Proteins

(A) Reticulocyte lysate (12 $\mu$, containing pSug ${ }_{1-147}$ DHFR) was incubated with apyrase $(1.3 \mathrm{U} / \mathrm{ml}$, reactions $3-5)$ or an apyrase preparation that had been heated before use (corresponding to $1.3 \mathrm{U} / \mathrm{ml}$, reactions 1 and 2) for $20 \mathrm{~min}$ at $30^{\circ} \mathrm{C}$ and $20 \mathrm{~min}$ at $25^{\circ} \mathrm{C}$ and cooled to $0^{\circ} \mathrm{C}$. BSA-containing butfer $(12 \mu l)$ was then added. Reaction 4 received $5 \mathrm{mM}$ ATP. Reaction 5 received $5 \mathrm{mM}$ GTP. All reactions were incubated for $10 \mathrm{~min}$ at $25^{\circ} \mathrm{C}$ and cooled to $0^{\circ} \mathrm{C}$. Reactions 4 and 5 again received the same amounts of ATP and GTP as described above. Reactions 2-5 were then treated with proteinase K (Prot K) $(1 \mu \mathrm{g} / \mathrm{ml}$ final concentration). Samples were resolved by SDS-polyacrylamide gel electrophoresis. Undigested pSu9 ${ }_{1-14 T}$-DHFR fusion protein was quantified by densitometry

(B) The experiment was performed as described for (A), with the following modifications. Reticulocyte lysate $(50 \mu \mathrm{l}$, containing precursor to ADP/ATP carrier synthesized out of poly(A) ${ }^{+}$RNA) was incubated with apyrase $(30 \mathrm{U} / \mathrm{ml}$, reactions $2,3,5,6,8$, and 9 ) or an apyrase preparation that had been heated before use (corresponding to $30 \mathrm{U} / \mathrm{ml}$, reactions 1,4 , and 7 ); $220 \mu$ of BSA-containing butfer was added. Reactions 3,6 , and 9 received $8 \mathrm{mM}$ GTP. The concentrations of proteinase $K$ were as indicated. ADP/ATP carrier was immunoprecipitated and quantified by densitometry of the fluorograms.

presequences but different mature protein parts shows different sensitivity toward removal of NTPS.

\section{NTPs Decrease the Protease Resistance of Precursor Proteins in Rabbit Reticulocyte Lysate}

Resistance against proteinase $\mathrm{K}$ has been used as a criterion for the folding state of a protein (see Introduction). The fusion protein pSu9 ${ }_{1-147}$-DHFR was synthesized in rabbit reticulocyte lysate (Figure $7 A$, reaction 1 ) and treated with proteinase $K$ at a concentration that degraded 
A) AtPase $F, \beta$

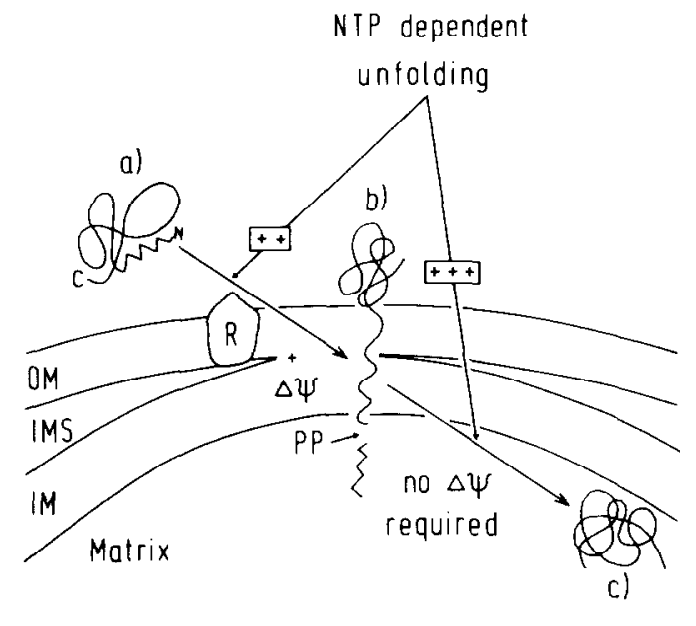

B) ADP/ATP carrier

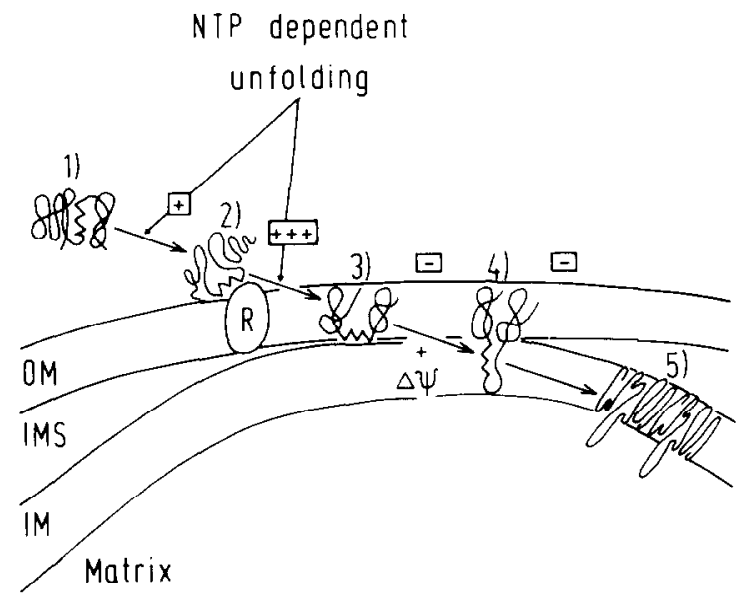

Figure 8. Distinct Steps on the Import Pathway of $F_{1} \beta$ and ADP/ATP Carrier into Mitochondria Require NTPs

The requirements for NTPs are indicated in squares from high requirement $(+++)$ to no requirement $(-)$. The various translocational intermediates are as described in the text and as published previously (Schleyer and Neupert, 1985; Pfanner and Neupert, 1987b). The topology of the mature ADP/ATP carrier in the inner membrane was drawn as proposed by Bogner et al. $(1982,1986)$. OM, outer mitochondrial membrane; IMS, intermembrane space; IM, inner membrane; $N$, amino terminus; $C$, carboxyl terminus; R, receptor; PP, processing peptidase; $\Delta \psi$, membrane potential.

$70 \%$ of the precursors (Figure $7 \mathrm{~A}$, reaction 2). Pretreatment of the reticulocyte lysate (containing the precursor) with apyrase increased the protease resistance of the precursors (Figure 7A, reaction 3). Readdition of ATP or GTP decreased the protease resistance to the control value (Figure $7 A$, reactions 4 and 5). Similarly, pretreatment with apyrase increased the protease resistance of the precursor to the ADPIATP carrier (Figure 7B, reactions 5 and 8 ); the protease concentrations were such that $70 \%$ (reaction 4) and $85 \%$ (reaction 7 ) of the precursors were degraded under control conditions. Readdition of NTPS decreased the protease resistance (Figure $7 \mathrm{~B}$, reactions
6 and 9). Thus, the presence of NTPs seems to influence the folding state of mitochondrial precursor proteins, i.e., promote unfolding.

\section{Discussion}

The import of several mitochondrial precursor proteins was shown to need both $\Delta \psi$ and NTPs. Distinct steps on the import pathways of $F_{1} \beta$ (Schleyer and Neupert, 1985) and ADPIATP carrier (Pfanner and Neupert, 1987b) were investigated for the requirement of NTPS. The results are summarized in Figure 8.

Transport of the cytosolic precursor to $F_{1} \beta$ (Figure $8 A$, stage a) to a translocation intermediate that reaches from the outside of the outer membrane into the matrix, such that the presequence can be cleaved off by the processing peptidase (stage b), requires NTPs. Further transport of the large carboxy-terminal portion from the cytosol into the matrix (stage c) requires higher levels of NTPs in a step that can occur in the absence of $\Delta \psi$.

Binding of the cytosolic precursor to the ADPIATP carrier (Figure 8B, stage 1) to receptor sites on the mitochondrial surface (stage 2) shows a (slight) dependence on NTPs. Insertion of the precursor into the outer membrane (stage 3) requires higher levels of NTPs. These steps can take place in the absence of $\Delta \psi$. The $\Delta \psi$-dependent entrance of the precursor into the inner membrane via translocation contact sites (stage 4), the completion of translocation into the inner membrane, and the assembly to the dimeric form (stage 5), however, are stimulated by removal of NTPs. Since the precursor to the ADP/ATP carrier is synthesized without a cleavable presequence, it is clear that the proteolytic processing of precursors is not the primary reason for the need of NTPs. A requirement for NTPs has also been shown for the import of porin into the outer membrane; this import occurs without proteolytic cleavage and is independent of $\Delta \psi$ (Kleene, Pfanner, Pfaller, Sebald, Neupert, and Tropschug, submitted).

The import of three precursors, each containing the presequence of $F_{0}$-ATPase subunit 9 but different mature protein parts, was investigated for requirement of NTPs. Despite that they supposedly use the same import sites, their imports show different requirements for NTPS.

In summary, several steps in the import of proteins into mitochondria require NTPs. The common feature of these steps appears to be the translocation of precursor domains from the cytosol onto or into the mitochondrial outer membrane. The complete insertion of precursors into the outer membrane needs higher levels of NTPs than either partial insertion or binding to receptor sites on the mitochondrial surface. The results are not consistent with models that explain the requirement for NTPS only by modification of the mitochondria, e.g., by phosphorylation of receptors or of other components of the mitochondrial import machinery, or by providing energy for the action of mitochondrial transport proteins. We have suggested as a possible explanation for this pleiotropic effect that the cytosolic conformation of mitochondrial precursor proteins is modified by the aid of NTPs (Pfanner and Neupert, 1986). Eilers and Schatz (1986) have shown that a high degree of tertiary structure hinders the import of a protein 
into mitochondria. Using resistance against digestion by proteinase $K$ as a criterion for the folding state of mitochondrial precursor proteins, we could indeed show that the presence of NTPs leads to an unfolding of the precursors. Thus, the role of NTPs includes cytosolic unfolding of precursors or precursor parts to make them competent for translocation into the mitochondrial membranes. Modifications of the mitochondrial membranes in addition to cytosolic conformational changes, however, cannot be excluded.

How do NTPs modulate the conformation of precursor proteins? The data reported here are consistent with proposed cytosolic activities able to unfold proteins (Rothman and Kornberg, 1986; Zimmermann and Meyer, 1986). We suggest the following model: cytosolic protein(s) binds to mitochondrial precursor proteins and keeps them in import-competent conformation, thereby preventing the (mis)folding of precursors, which would otherwise make them import-incompetent. The precursors can then bind to receptor sites and be inserted into the outer membrane. In these processes, the hydrolysis of high energy phosphate bonds of NTPs is necessary. Since the insertion into the membrane requires folding of large precursor parts into competent conformation, this step needs higher amounts of NTPS than the binding to receptors. For the completion of translocation of precursors from the outer into or across the inner membrane, however, the cytosolic protein(s) must be removed. Depletion of NTPs from mitochondria may facilitate the removal, thereby stimulating the completion of import. Additional studies have to clarify the nature and exact function of the putative cytosolic cofactor(s) and determine whether they are related to cofactors described earlier (Argan et al., 1983; Miura et al., 1983; Firgaira et al., 1984; Ohta and Schatz, 1984; Argan and Shore, 1985; Pfanner and Neupert, 1987b). It is not yet known which form of NTPs, e.g., ATP or GTP, is the direct energy source.

The import of physiological mitochondrial precursor proteins is not the only example in which NTPs are needed. Fusion proteins containing nonmitochondrial polypeptides also show this requirement, suggesting a general mechanism for the unfolding of proteins. Furthermore, NTP-dependent unfolding proteins could also be necessary for the translocation of proteins across other biological membranes. Requirements for NTPs have been reported for protein export in E. coli (Chen and Tai, 1985; Geller et al., 1986), protein import into chloroplasts (Grossman et al., 1980; Flügge and Hinz, 1986), and protein translocation across the membrane of the endoplasmic reticulum (Hansen et al., 1986; Mueckler and Lodish, 1986; Rothblatt and Meyer, 1986; Waters and Blobel, 1986; Schlenstedt and Zimmermann, 1987; Wiech et al., 1987). Transport of proteins from the mitochondrial matrix into or across the inner membrane, which is analogous to protein export in E. coli (Hartl et al., 1986; Pfanner and Neupert, 1987a), might also require NTPs.

\section{Experimental Procedures}

In Vitro Import of Precursors into Mitochondria

The following procedures were performed as published previously: growth of N. crassa (wild type 74A) (Schleyer et al., 1982); isolation of mitochondria by Percoll density gradient centrifugation (Hartl et al. 1986; Pfanner and Neupert, 1986), except that the mitochondria were washed twice in SEM medium (250 mM sucrose, $1 \mathrm{mM}$ EDTA, $10 \mathrm{mM}$ 3-(N-morpholino)propanesulfonic acid [MOPS], adjusted to $\mathrm{pH} 7.2$ with $\mathrm{KOH}$ ); protein determination (Bradford, 1976); synthesis of mitochondrial precursor proteins in rabbit reticulocyte lysates (Pelham and Jackson, 1976; Schleyer et al., 1982; Pfanner and Neupert, 1985); preparation of "no synthesis lysates" lacking mitochondrial precursor proteins (Pfanner and Neupert, 1985); treatment of reticulocyte lysate and mitochondria with apyrase (Pfanner and Neupert, 1986); addition of antimycin A, oligomycin, valinomycin, potassium ascorbate, TMPD, and nucleoside phosphates; treatment with proteinase $\mathrm{K}$ or trypsin and addition of PMSF and soybean trypsin inhibitor; reisolation of mitochondria by centrifugation (Pfanner and Neupert, 1986, 1987b); assessment of import of ADPIATP carrier by hydroxylapatite chromatography (Schleyer and Neupert, 1984; Pfanner and Neupert, 1987b); immunoprecipitation of ADPIATP carrier, $F_{1} \beta$, and ATPase subunit 9 and SDS-polyacrylamide gel electrophoresis (Schleyer et al., 1982; Pfanner and Neupert, 1985); fluorography (Chamberlain, 1979) and quantitation of the fluorograms by densitometry (Pfanner and Neupert. 1985).

The reaction volume for binding and import of precursors at $25^{\circ} \mathrm{C}$ was $200 \mu \mathrm{l}$, including a buffer containing $250 \mathrm{mM}$ sucrose, $80 \mathrm{mM} \mathrm{KCl}$, $5 \mathrm{mM} \mathrm{MgCl}_{2}, 10 \mathrm{mM}$ MOPS and $3 \%$ (w/V) BSA, adjusted to $\mathrm{pH} 7.2$ with $\mathrm{KOH}$. The amounts of mitochondria and reticulocyte lysate added were such that the samples contained $25 \mu \mathrm{g}$ of mitochondrial protein and $75 \mu \mathrm{l}$ of reticulocyte lysate. All reactions were made chemically identical by adding the same volume of reagent-free solvent to the control samples. After the binding and import reactions, the reisolated mitochondria were washed in SEM medium or in the described BSAcontaining buffer and transferred to new sample tubes. In some experiments, the wash buffers contained valinomycin and apyrase $(0.2 \mathrm{U} / \mathrm{ml})$. Each experiment was performed at least 3 times; the variations between the experiments were less than $10 \%$.

\section{Construction of Fusion Proteins}

\section{Fusion Protein pSu9 1-69-DHFA}

The vector used was pDS5/2, which contains the cDNA coding for mouse DHFR downstream of a T5 promoter (Stueber ot al., 1984). It was linearized at the unique BamHI site in front of the DHFR gene and treated with $S 1$ nuclease, Klenow polymerase, and calf intestinal phosphatase (Maniatis et al., 1982). A full-length cDNA coding for subunit 9 of $F_{0}$-ATPase was isolated from a $N$. crassa library constructed according to Gubler and Hoffman (1983). According to the published sequence of subunit 9 cDNA (Viebrock et al., 1982), it contains two Sau3A sites, one of which cleaves in the triplet coding for glutamic acid-the fourth amino acid of the mature subunit 9 (Sebald et al. 1980). The cDNA was cut with Sau3A, and a 280 bp Pstl-Sau3A piece, which contained the coding region for the entire presequence plus 5 'untranslated region, was isolated, treated with $\mathrm{S} 1$ nuclease and Klenow polymerase, and ligated into a pDS5/2 vector that was treated as described above. Transformation of $\mathrm{E}$. coli strain $\mathrm{DH} \uparrow$ was done according to Hanahan (1983). Plasmld DNAs of the resulting clones which had EcoRl-HindIII inserts of about 950 bp (280 bp from the presequence plus approximately 670 bp from the DHFR cDNA), were sequenced according to Chen and Seeburg (1985), using a synthetic DHFR specific primer, 5'-CCATATTTTGGGACAC-3', corresponding to nucleotides 48-32 of the antisense strand of the coding region of DHFR. The amino acid sequence at the junction between the subunit 9 presequence and DHFR reads FQKRAYSSdgiMVRP (amino acids in capital letters correspond to subunit 9 [left] or DHFR sequences [right] separated by the amino acids introduced by cloning [lower case]; $Y$ is the first amino acid of the mature subunit 9 [Sebald et al., 1980]). Transcription with E. coli RNA polymerase, capping, and translation of the resulting RNAs were done as described (Stueber et al., 1984). For the in vitro import reactions, "no synthesis lysate" was included such that each sample contained $75 \mu$ of reticulocyte lysate.

Fusion Protein pSu9 1-147 DHFR

The cDNA coding for subunit 9 (see above) was inserted in the correct orientation into the Pstl site of pDS5 (Stueber et al., 1984), resulting in plasmid pl16/23. Plasmid pl16/23 was treated with Nsil, which cuts 5 nucleotides downstream of the TAA stop codon of subunit 9 (Viebrock et al., 1982), resulting in a 3'-overhanging piece of 4 nucleotides. We also used a high concentration of $\mathrm{S} 1$ nuclease $(5 \mathrm{U}$ per $\mu \mathrm{g}$ 
of DNA) to resect a piece of double-stranded DNA into the stop codon. Afterwards, the plasmid was treated with Klenow polymerase and calf intestinal phosphatase. DHFR cDNA was cut out of pDS5/2 as a BamHI-HindIII fragment, treated with $S 1$ nuclease and Klenow polymerase, and blunt end-ligated into the vector described above. Correct orientation of the DHFR CDNA and the sequence of the junction were determined by double-stranded DNA sequencing, using the DHFRspecific primer mentioned above. The amino acid sequence around the junction reads AKFTygiMVRP (amino acids in capital letters correspond to the C-terminal part of the subunit 9 [left] and the $\mathrm{N}$-terminal part of DHFR [right]; the TAA stop codon of subunit 9 was changed by the cloning procedure into a TAC tyrosine codon; amino acids in lower case were introduced by the cloning procedure).

\section{Acknowledgments}

We thank Dr. W. Sebald for advice in preparing the N. crassa cDNA library, Dr. R. Mertz for providing oligonucleotides, Drs. D. Stueber and $H$. Bujard for gift of pDS plasmids, $H$. Müller for help in constructing the pSu9 1-147 $^{-D H F R}$ fusion protein, and Dr. D. W. Nicholson for critically reading the manuscript. We are grateful to $C$. Forster and I. Kohl for expert technical assistance. This work was supported by the Deutsche Forschungsgemeinschaft (grant $\mathrm{Ne}$ 101/19-2; Sonderforschungsbereich 184, project B1), the Genzentrum München (project 7), the Fonds der Chemischen Industrie, and the Münchner Medizinische Wochenschrift.

The costs of publication of this article were defrayed in part by the payment of page charges. This article must therefore be hereby marked "advertisement" in accordance with 18 U.S.C. Section 1734 solely to indicate this fact.

Received April 6, 1987.

\section{References}

Arends, H., and Sebald, W. (1984). Nucleotide sequence of the cloned mRNA and gene of the ADPIATP carrier from Neurospora crassa. EMBO J. 3, 377-382.

Argan, C., and Shore, G. C. (1985). The precursor to ornithine carbamyl transferase is transported to mitochondria as a $5 \mathrm{~S}$ complex containing an import factor. Biochem. Biophys. Res. Commun. 131, 289-298.

Argan, C., Lusty, C. J., and Shore, G. C. (1983). Membrane and cytosolic components affecting transport of the precursor for ornithine carbamyltransferase into mitochondria. J. Biol. Chem. 258, 6667-6670.

Bogner, W., Aquila, H., and Klingenberg, M. (1982). Surface labeling of membrane-bound ADP/ATP carrier by pyridoxal phosphate. FEBS Lett. 146, 259-261.

Bogner, W., Aquila, H., and Klingenberg, M. (1986). The transmembrane arrangement of the ADP/ATP carrier as elucidated by the lysine reagent pyridoxal 5-phosphate. Eur. J. Biochem. 161, 611-620.

Böhni, P., Gasser, S., Leaver, C., and Schatz, G. (1980). A matrixlocalized mitochondrial protease processing cytoplasmically-made precursors to mitochondrial proteins. In The Organization and Expression of the Mitochondrial Genome, A. M. Kroon and C. Saccone, eds. (Amsterdam: Elsevier/North Holland), pp. 423-433.

Böhni, P. C., Daum, G., and Schatz, G. (1983). Import of proteins into mitochondria: partial purification of a matrix-localized protease in volved in cleavage of mitochondrial precursor polypeptides. J. Biol. Chem. 258, 4937-4943.

Bradford, M. M. (1976). A rapid and sensitive method for the quantitation of microgram quantities of protein utilizing the principle of proteindye binding. Anal. Biochem. 72, 248-254.

Chamberlain, J. P. (1979). Fluorographic detection of radioactivity in polyacrylamide gels with the water-soluble fluor, sodium salicylate. Anal. Biochem. 98, 132-135

Chen, E. J., and Seeburg, P. H. (1985). Supercoil sequencing: a fast and simple method for sequencing plasmid DNA. DNA 4, 165-170.

Chen, L., and Tai, P. C. (1985). ATP is essential for protein translocation into Escherichia coli membrane vesicles. Proc. Natl. Acad. Sci. USA $82,4384-4388$.
Conboy, J. G., Fenton, W. A., and Rosenberg, L. E. (1982). Processing of pre-ornithine transcarbamylase requires a zinc-dependent protease localized to the mitochondrial matrix. Biochem. Biophys. Res. Commun. 105, 1-7.

Eilers, M., and Schatz, G. (1986). Binding of a specific ligand inhibits import of a purified precursor protein into mitochondria. Nature 322 . 228-232.

Emr, S. D., Vassarotti, A., Garrett, J., Geller, B. L., Takeda, M., and Douglas, M. C. (1986). The amino terminus of the yeast $F_{1}$-ATPase $\beta$ subunit precursor functions as a mitochondrial import signal. J. Cell Biol. 102, 523-533.

Firgaira, F. A., Hendrick, J. P., Kalousek, F., Kraus, J. P., and Rosenberg, L. E. (1984). RNA required for import of precursor proteins into mitochondria. Science 226, 1319-1322.

Flügge, U. I., and Hinz, G. (1986). Energy dependence of protein translocation into chloroplasts. Eur. J. Biochem. 160, 563-570.

Frank, R., Trosin, M., Tomasselli, A. G., Schulz, G. E., and Schirmer, R. H. (1984). Mitochondrial adenylate kinase (AK2) from bovine heart. Homology with the cytosolic isoenzyme in the catalytic region. Eur. J. Biochem. 141, 629-636.

Gasser, S. M., Daum, G., and Schatz, G. (1982). Import of proteins into mitochondria. Energy-dependent uptake of precursors by isolated mitochondria. J. Biol. Chem. 257, 13034-13041.

Geller, B. L., Movva, N. R., and Wickner, W. (1986). Both ATP and the electrochemical potential are required for optimal assembly of proOmpA into Escherichia coli inner membrane vesicles. Proc. Natl. Acad. Sci. USA 83, 4219-4222.

Grossman, A., Bartlett, S., and Chua, N. H. (1980). Energy-dependent uptake of cytoplasmically synthesized polypeptides by chloroplasts Nature 285, 625-628.

Gubler, U., and Hoffman, B. J. (1983). A simple and very efficient method for generation of CDNA libraries. Gene 25, 263-269.

Hanahan, D. (1983). Studies on transformation of Escherichia coli with plasmids. J. Mol. Biol. 166, 557-580.

Hansen, W., Garcia, P. D., and Walter, P. (1986). In vitro protein translocation across the yeast endoplasmic reticulum: ATP-dependent posttranslational translocation of the prepro-a-factor. Cell 45, 397-406.

Harmey, M. A., and Neupert, W. (1985). Intracellular transport of mitochondrial membrane proteins. In The Enzymes of Biological Membranes, Vol. 4, A. Martonosi, ed. (New York: Plenum Publishing Co.), pp. 431-464

Hartl, F.-U., Schmidt, B., Wachter, E., Weiss, H., and Neupert, W. (1986). Transport into mitochondria and intramitochondrial sorting of the $\mathrm{Fe} / \mathrm{S}$ protein of ubiquinol-cytochrome c reductase. Cell 47, 939951.

Hay, R., Böhni, P., and Gasser, S. (1984). How mitochondria import proteins. Biochim. Biophys. Acta 779, 65-87.

Hennig, B., and Neupert, W. (1981). Assembly of cytochrome c: apocytochrome $\mathrm{c}$ is bound to specific sites on mitochondria before its conversion to holocytochrome c. Eur. J. Biochem. 121, 203-212.

Hennig, B., Köhler, H., and Neupert, W. (1983). Receptor sites involved in posttranslational transport of apocytochrome $c$ into mitochondria: specificity, affinity and number of sites. Proc. Natl. Acad. Sci. USA 80, 4963-4967.

Horwich, A. L., Kalousek, F., Mellman, I., and Rosenberg, L. E. (1985). A leader peptide is sufficient to direct mitochondrial import of a chimeric protein. EMBO J. 4, 1129-1135.

Hurt, E. C., Pesold-Hurt, B., and Schatz, G. (1984). The cleavable prepiece of an imported mitochondrial protein is sufficient to direct cytosolic dihydrofolate reductase into the mitochondrial matrix. FEBS Lett. 178, 306-310

Hurt, E. C., Pesold-Hurt, B., Suda, K., Oppliger, W., and Schatz, G (1985). The first twelve amino acids (less than half of the pre-sequence) of an imported mitochondrial protein can direct mouse cytosolic dihydrofolate reductase into the yeast mitochondrial matrix. EMBO J. 4, 2061-2068.

Jaenicke, R., and Rudolph, R. (1986). Refolding and association of oligomeric proteins. Meth. Enzymol. 131, 218-250. 
Keng, T., Alani, E., and Guarente, L. (1986). The nine amino-terminal residues of $\delta$-aminolevulinate synthase direct $\beta$-galactosidase into the mitochondrial matrix. Mol. Cell. Biol. 6, 355-364.

Kolanski, D. M., Conboy, J. G., Fenton, W. A., and Rosenberg, L. E. (1982). Energy-dependent translocation of the precursor of ornithine transcarbamylase by isolated rat liver mitochondria. J. Biol. Chem. 257, 8467-8471.

Maniatis, T., Fritsch, E. F., and Sambrook, J. (1982). Molecular Cloning. A Laboratory Manual (Cold Spring Harbor, New York: Cold Spring Harbor Laboratory).

McAda, P. C., and Douglas, M. G. (1982). A neutral metallo-endoprotease involved in the processing of an $F_{1}$-ATPase subunit precursor in mitochondria. J. Biol. Chem. 257, 3177-3182.

Miura, S., Mori, M., Amaya, Y., and Tatibana, M. (1982). A mitochondrial protease that cleaves the precursor of ornithine carbamoyl transferase. Eur. J. Biochem. 122, 641-647.

Miura, S., Mori, M., and Tatibana, M. (1983). Transport of ornithine carbamoyltransferase precursor into mitochondria: stimulation by potassium ion, magnesium ion, and a reticulocyte cytosolic protein(s). J. Biol. Chem. 258, 6671-6674.

Mueckler, M., and Lodish, H. F. (1986). Post-translational insertion of a fragment of the glucose transporter into microsomes requires phosphoanhydride bond cleavage. Nature 322, 549-552.

Nicholls, D. G. (1982). Bioenergetics (London: Academic Press).

Nunberg, J. H., Kaufman, R. J., Chang, A. C. Y., Cohen, S. N., and Schimke, R. T. (1980). Structure and genomic organization of the mouse dihydrofolate reductase gene. Cell 19, 355-364.

Ohta, S., and Schatz, G. (1984). A purified precursor polypeptide requires a cytosolic protein fraction for import into mitochondria. EMBO J. 3, 651-657.

Pelham, H. R. B., and Jackson, R. J. (1976). An efficient mRNAdependent translation system from reticulocyte lysates. Eur. J. Biochem. 67, 247-256.

Pfaller, R., Freitag. H., Harmey, M. A., Benz, R., and Neupert, W. (1985). A water-soluble form of porin from the mitochondrial outer membrane of Neurospora crassa: properties and relationship of the biosynthetic precursor form. J. Biol. Chem. 260, 8188-8193.

Pfanner, N., and Neupert, W. (1985). Transport of proteins into mitochondria: a potassium diffusion potential is able to drive the import of ADPIATP carrier. EMBO J. 4, 2819-2825.

Pfanner, N., and Neupert, W. (1986). Transport of $F_{1}$-ATPase subunit $\beta$ into mitochondria depends on both a membrane potential and nucleoside triphosphates. FEBS Lett. 209, 152-156.

Pfanner, N., and Neupert, W. (1987a). Biogenesis of mitochondrial energy transducing complexes. In Current Topics in Bioenergetics, Vol. 15, C. P. Lee, ed. (New York: Academic Press), in press.

Pfanner, N., and Neupert, W. (1987b). Distinct steps in the import of ADPIATP carrier into mitochondria. J. Biol. Chem., in press.

Randall, L. L., and Hardy, S. J. S. (1986). Correlation of competence for export with lack of tertiary structure of the mature species: a study in vivo of maltose-binding protein in $\mathrm{E}$. coli. Cell 46, 921-928.

Riezman, H., Hay, R., Witte, C., Nelson, N., and Schatz, G. (1983). Yeast mitochondrial outer membrane specifically binds cytoplasmically-synthesized precursors of mitochondrial proteins. EMBO J. 2, 1113-1118.

Roise, D., Horvath, S. J., Tomich, J. M., Richards, J. H., and Schatz, $G$. (1986). A chemically synthesized pre-sequence of an imported mitochondrial protein can form an amphiphilic helix and perturb natural and artificial phospholipid bilayers. EMBO J. 5, 1327-1334.

Rothblatt, J. A., and Meyer, D. I. (1986). Secretion in yeast: translocation and glycosylation of prepro- $\alpha$-factor in vitro can occur via an ATP. dependent post-translational mechanism. EMBO J. 5, 1031-1036.

Rothman, J. E., and Kornberg, R. D. (1986). An unfolding story of protein translocation. Nature 322, 209-210.

Schlenstedt, G., and Zimmermann, R. (1987). Import of frog prepropeptide GLa into microsomes requires ATP but does not involve docking protein or ribosomes. EMBO. J. 6, 699-703.
Schleyer, M., and Neupert, W. (1984). Transport of ADPIATP carrier into mitochondria: precursor imported in vitro acquires functional properties of the mature protein. J. Biol. Chem. 259, 3487-3491.

Schleyer, M., and Neupert, W. (1985). Transport of proteins into mitochondria: translocational intermediates spanning contact sites between outer and inner membranes. Cell 43, 339-350.

Schleyer, M., Schmidt, B., and Neupert, W. (1982). Requirement of a membrane potential for the posttranslational transfer of proteins into mitochondria. Eur. J. Biochem. 125, 109-116.

Schmidt, B., Wachter, E., Sebald, W., and Neupert, W. (1984). Processing peptidase of Neurospora mitochondria. Two-step cleavage of imported ATPase subunit 9. Eur. J. Biochem. 144, 581-588.

Schmidt, B., Pfaller, R., Pfanner, N., Schleyer, M., and Neupert, W (1985). Transport of proteins into mitochondria: receptors, recognition and transmembrane movement of precursors. In Achievements and Perspectives of Mitochondrial Research, Vol. II, E. Quagliarielło, E. C Slater, F. Palmieri, C. Saccone, and A. M. Kroon, eds. (Amsterdam: EIsevier Science Publishers), pp. 389-396.

Schwaiger, M., Herzog, V., and Neupert, W. (1987). Characterization of translocation contact sites involved in the import of mitochondrial proteins. J. Cell Biol., in press.

Sebald, W., Machleidt, W., and Wachter, E. (1980). N, N'-dicyclohexylcarbodiimide binds specifically to a single glutamyl residue of the pro teolipid subunit of the mitochondrial adenosinetriphosphatases from Neurospora crassa and Saccharomyces cerevisiae. Proc. Natl. Acad. Sci. USA $77,785-789$.

Stueber, D., Ibrahimi, I., Cutler, D., Dobberstein, B., and Bujard, H. (1984). A novel in vitro transcription-translation system: accurate and efficient synthesis of single proteins from cloned DNA sequences. EMBO J. 3, 3143-3148.

van Loon, A. P. G. M., and Young, E. T. (1986). Intracellular sorting of alcohol dehydrogenase isoenzymes in yeast: a cytosolic location reflects absence of an amino-terminal targeting sequence for the mitochondrion. EMBO J. 5, 161-165.

van Loon, A. P. G. M., Brändli, A. W., and Schatz, G. (1986). The presequences of two imported mitochondrial proteins contain information for intracellular and intramitochondrial sorting. Cell 44, 801-812.

Viebrock, A., Perz, A., and Sebald, W. (1982). The imported preprotein of the proteolipid subunit of the mitocl. ndrial ATP synthase from Neurospora crassa. Molecular cloning and sequencing of the mRNA EMBO J. 1, 565-571.

Waters, M. G., and Blobel, G. (1986). Secretory protein translocation in a yeast cell-free system can occur posttranslationally and requires ATP hydrolysis. J. Cell Biol. 102, 1543-1550.

Wiech, H., Sagstetter, M., Müller, G., and Zimmermann, R. (1987). The ATP-requiring step in assembly of $\mathrm{M} 13$ procoat protein into micro somes is related to preservation of a transport competent conformation. EMBO J. 6, 1011-1016.

Wikstrom, M., and Krab, K. (1982). Proton-pumping cytochrome c oxidase. Biochim. Biophys. Acta 549, 177-222.

Zimmermann, R., and Meyer, D. I. (1986). 1986: a year of new insights into protein translocation across membranes. Trends Biochem. Sci. 11, 512-515.

Zimmermann, R., Paluch, U., Sprinzl, M., and Neupert, W. (1979). Cellfree synthesis of the mitochondrial ADP/ATP carrier protein of Neurospora crassa. Eur. J. Biochem. 99, 247-252.

Zwizinski, C., and Neupert, W. (1983). Precursor proteins are transported into mitochondria in the absence of proteolytic cleavage of the additional sequences. J. Biol. Chem. 258, 13340-13346.

Zwizinski, C., Schleyer, M., and Neupert, W. (1983). Transfer of proteins into mitochondria. Precursor to the ADP/ATP carrier binds to receptor sites on isolated mitochondria. J. Biol. Chem. 258, 4071-4074

Zwizinski, C., Schleyer, M., and Neupert, W. (1984). Proteinaceous receptors for the import of mitochondrial precursor proteins. J. Biol. Chem. 259, 7850-7856. 